\title{
Chapter 9 \\ Using Diffusion of Innovations Theory to Modify Library OER Interventions During the COVID-19 Pandemic
}

\author{
Kathy Essmiller \\ Oklahoma State University, USA
}

\begin{abstract}
The high cost of commercial textbooks has been well documented. To help alleviate the impact of those costs, the Oklahoma State University (OSU) Library identified exploration and support of open educational resources (OER) as a priority in their strategic plan. The OSU Library OER Librarian used human performance technology analysis findings to select and design interventions for inclusion in the library's support of OER. When OSU abruptly switched mid-Spring 2020 to emergency remote teaching in response to the COVID-19 pandemic, the library was faced with the need to modify interventions designed for face-to-face interaction to engage and support faculty instructors in online spaces. This chapter uses diffusions of innovations theory to describe how the library made meaning of and anticipated challenges and to share how the library designed and implemented modified interventions.
\end{abstract}

\section{INTRODUCTION}

The high cost of commercial textbooks has been well documented (Jenkins et al, 2020). Open educational resources (OER) have been defined by the United Nations Educational, Scientific and Cultural Organization (UNESCO) as "teaching, learning and research materials that make use of appropriate tools, such as open licensing, to permit their free reuse, continuous improvement and repurposing by others for educational purposes" (Miao et al., 2019, p. 9). Use of OER can improve student access to meaningful learning experiences, facilitate innovative teaching and learning practices (Soper et al., 2018), and support academic freedom (Cuillier, 2018). Although faculty awareness of OER is increasing (Larson, 2020; Seaman \& Seaman, 2018), faculty continue to perceive barriers to their use which prevent wide-

DOI: 10.4018/978-1-7998-6449-3.ch009

Copyright $\odot$ 2021, IGI Global. Copying or distributing in print or electronic forms without written permission of IGI Global is prohibited. 
spread adoption (Walsh, 2020). Belikov and Bodily (2016) suggested these barriers might be eliminated if faculty were provided more information about OER, if faculty could more easily discover OER, and if faculty had clarity regarding the "difference between digital resources and OER" (p. 235).

As institutions of higher education see the value of OER in reducing the burden of costly course materials, they have turned to academic libraries to create and support initiatives through which they collaborate with faculty to encourage the creation and use of OER (Larson, 2020; Lashley et al., 2017). Academic libraries are seen as a good fit for the support of OER initiatives as they are generally already positioned as faculty partners, librarians have the requisite skills needed to discover and evaluate OER as information sources, and because many academic libraries have existing scholarly communications Open Access programs (Hess et al., 2016). The Oklahoma State University (OSU) Library is among the academic libraries that have taken a leadership role in developing initiatives through which faculty are supported in adopting, modifying, and creating OER (Essmiller et al., 2020)

To help alleviate the impact of costly commercial resources on university students, the OSU Library identified exploration and support of OER as a priority in its strategic plan (Essmiller et al., 2020). A private, one-time donation supported faculty creation of a limited number of OER textbooks, but once the funding was exhausted, the Library found itself struggling to transition to a consistent, sustainable OER program. The OSU Library hired a full-time OER Librarian, who used the findings of a human performance technology analysis (Van Tiem et al., 2012) to select interventions for inclusion in the Libraries long-term support of OER (Essmiller et al., 2020). These interventions included Library facilitated instruction about OER, provision of incentives and instructional design support to assist faculty in locating and adapting effective OER, and the development of and monthly meetings with a campus-wide OER working group. When OSU abruptly switched mid-Spring 2020 to emergency remote teaching in response to the COVID-19 pandemic, the Library was faced with the need to modify interventions designed for face-to-face interaction in order to engage and support faculty and instructors in online spaces. This paper describes challenges faced as the Library continued to provide services related to faculty and instructor use of OER to the OSU community. The lens of Diffusions of Innovations Theory (Rogers, 2003) is applied to describe how the Library made meaning of and anticipated challenges and to share how the Library designed and implemented modified interventions.

The purpose of this paper is to describe an OER Librarian's use of Diffusion of Innovations Theory to make meaning of and anticipate challenges the Library faced in spring 2020 associated with the COVID-19 pandemic. The challenges described relate in particular to continued efforts in support of the OSU Library's OER initiatives. The following sections will provide an overview of Diffusion of Innovations Theory, share definitions, characteristics, and potential benefits of OER, and present a description of how the COVID-19 Pandemic came to impact the Oklahoma State University Library.

\section{BACKGROUND}

\section{Diffusion of Innovations Theory}

Diffusions of Innovations Theory examines how innovations are developed, evaluated, adopted, and diffused through a system or organization (Rogers, 2003). Diffusion of innovations is the process through which "an innovation is communicated through certain channels over time among the members of a social system" (Rogers, 2003, p. 10). An innovation is an idea or practice perceived as new by individuals or 
organizations considering its adoption (Rogers, 2003). Individuals or organizations may choose to adopt an innovation after having become familiar with the innovation's attributes (see Table 1) and making decisions regarding its value to the organization (Rogers, 2003). An innovation is considered having diffused when an organization or system no longer perceives the idea or practice as new (Rogers, 2003).

Table 1. Attributes of innovations as described by Rogers (2003)

\begin{tabular}{|l|l|}
\hline & \multicolumn{1}{|c|}{ Attributes of Innovations } \\
\hline Relative Advantage & "the degree to which an innovation is perceived as being better than the idea it supersedes" (Rogers, 2003, p. 229) \\
\hline Compatibility & $\begin{array}{l}\text { "the degree to which an innovation is perceived as consistent with the existing values, past experiences, and needs } \\
\text { of potential adopters" (Rogers, 2003, p. 240) }\end{array}$ \\
\hline Complexity & $\begin{array}{l}\text { "the degree to which an innovation is perceived as relatively difficult to understand and use" (Rogers, 2003, p. } \\
\text { 257) }\end{array}$ \\
\hline Trialability & "the degree to which an innovation can be experimented with on a limited basis" (Rogers, 2003, p. 258) \\
\hline Observability & "the degree to which the results of an innovation are visible to others" (Rogers, 2003, p. 16) \\
\hline
\end{tabular}

OER involve ideas and practices used to create teaching and learning resources licensed for access, modification, dissemination, and retention at no additional cost to the end user (Miao et al. 2019; Reed \& Jahre, 2019; Sandy \& Mattern, 2018). In addition to benefits associated with affordability, OER provide faculty the freedom to customize teaching and learning resources to meet local classroom needs, allow students choice regarding whether they wish to interact with print or digital versions of the material (Wiley \& Hilton, 2018), and facilitate open practices which "democratize access to knowledge curation" (Nusbaum, 2020, p. 3). Although provision of access to educational resources is not perceived by systems of higher education as a new idea, the creation and use of OER involves practices and ideas faculty and instructors perceive as new (Larson, 2020; Seaman \& Seaman, 2018). This perception positions OER as an innovation undergoing the innovation-diffusion process within organizations of higher education.

Understanding where in the diffusion process an innovation is can help inform communication targeted to specific adopter categories (Rogers, 2003). Rogers (2003) standardized five adopter categories to describe the rate at which individuals within a system adopt an innovation. These five adopter categories are innovators, early adopters, early majority, late majority, and laggards (Rogers, 2003). Individuals within each of those categories are understood to have received communication about the innovation in different ways (Rogers, 2003). According to Rogers (2003), innovators and early adopters will likely have developed knowledge regarding the innovation through interaction with mass media channels. Early majority and late majority adopters will likely have developed knowledge regarding the innovation through interpersonal channels (Rogers, 2003). Findings of the OSU Library's human performance technology analysis suggested the diffusion of OER at OSU was underway but incomplete (Essmiller et al., 2020), and interventions were designed to use interpersonal channels to target potential early and late majority adopters (Rogers, 2003).

\section{Open Educational Resources}

Open Educational Resources (OER) are defined by UNESCO as "teaching, learning and research materials that make use of appropriate tools, such as open licensing, to permit their free reuse, continuous 
improvement and repurposing by others for educational purposes" (Miao et al., 2019, p. 9). Hilton (2019) described OER as resources used for teaching, learning, and/or research which are available in the public domain or have been released with an "intellectual property license" (p. 854) communicating the creator's willingness for others to freely use and repurpose the resources. Wiley described the characteristics of many OER in terms of whether they can be reused, retained, revised, remixed, and redistributed (Wiley, n.d.; Wiley \& Hilton, 2018). While the term 'OER' is commonly considered having first been devised at the Forum on the Impact of Open Courseware for Higher Education in Developing Countries in 2002 (Hess et al., 2016; Mishra, 2017; Miao et al., 2019), sharing and customization of resources whose creators have freely shared them for others' use have long been embedded in educator practice (Downes, 2018).

Courses taught using OER rather than commercial textbooks can alleviate financial barriers inhibiting student access to necessary learning materials (Jenkins et al., 2020; Soper et al., 2018). In a study establishing financial barriers to learning materials as a social justice concern (Jenkins et al., 2020), 89\% percent of the over 700 undergraduate students surveyed were shown to have "experienced increased stress levels due to textbook costs" (p. 5). Students use a variety of strategies to mitigate the impact of textbook costs on their educational experiences including not purchasing required course materials (Hilton, 2019), delaying purchase of required course materials, sharing course materials, enrolling in fewer courses, or even changing majors in an effort to find a course of study requiring less expensive textbooks (Jenkins et al., 2020; OkState Library, 2019).

The use of OER can facilitate innovative teaching and learning practices (Bali et al., 2020; Soper et al., 2018). The flexibility afforded by the open licensing invites development of teaching and learning experiences which move "beyond a content-centered approach" (Cronin, 2017). Students themselves can share in the knowledge creation experience by interacting with the content, their teacher, and each other to create artifacts of value beyond the classroom (DeRosa et al., 2018). For example, Nusbaum (2020) leveraged the affordances of OER to involve students in updating the content of one chapter of a course's OpenStax Psychology text. Student submitted revisions resulted in diversified content which was found to ameliorate a "reduced sense of belonging" (Nusbaum, 2020, p. 1) reported by first-generation students reading the un-revised chapter. Another example is David Squires' student/faculty collaboration (DiRosa et al., 2018). Squires worked with students in his Intro to Digital Technology and Culture Course to create two OER texts covering cultural studies and social media. The students researched copyright and publishing as well as topics associated with social media. In addition to being able to achieve learning objectives via authentic, real-life experiences, Squires found that students shared more knowledge as part of the content curation/creation process than he typically saw in class discussions (DiRosa et al., 2018), suggesting increased student engagement as a result of teaching and learning practices facilitated by his use of OER.

Faculty and instructors supporting learning experiences with OER may find a greater degree of academic freedom than is present when using commercial textbooks designed for mass institutional consumption. The customizability of OER allows faculty and instructors to draw on their own scholarly expertise to establish goals, design and implement activities tailored to cultivate and assess learning appropriate for their particular students and style of teaching (Cuillier, 2018; DiSanto et al., 2020). This faculty and instructor "agency over course material selection and design" (Santiago \& Ray, 2020, p. 22) can provide a cornerstone for OER advocacy (Cuillier, 2018). 


\section{The COVID-19 Pandemic and Oklahoma State University Library}

In late December 2019, faculty at the OSU Library began hearing of a potentially new respiratory illness having surfaced overseas. Information about the illness was not prominently shared on national or local news networks, however, so as campus closed for winter break there was little worry that the illness might have significant impact on the OSU campus. Students returned to campus from winter break in mid-January, and the Spring 2020 semester began as planned. As the Spring 2020 semester progressed, awareness among Library faculty regarding the respiratory illness grew somewhat with the news of mandated quarantine of Wuhan, China, as one of the librarians had family living in that community. The faculty discussed sending masks or other aid to the librarians' family member as well as how to provide support for OSU international students with family impacted overseas. Otherwise, concern for the illness' local impact continued to be minor, although Library faculty with spring semester international travel plans had some anxiety about its impact on upcoming conferences.

In early February 2020, the International Committee on Taxonomy of Viruses announced SARS-CoV-2 as the official name for the virus causing the illness then considered a primarily respiratory disease. The World Health Organization named the disease caused by the SARS-CoV-2 virus COVID-19 in an effort to mitigate "unnecessary fear" which might accompany the illness' identification as genetically related to SARS (World Health Organization, n.d.). A February 25, 2020 update from the Center for Disease Control and Prevention (CDC) describing the situation as "rapidly evolving with community spread" prompted OSU to ban university travel to countries designated by the CDC as Level 3, where the COVID-19 risk was high (Oklahoma State University, 2020). On March 3, 2020, OSU cancelled travel abroad programs to Italy, and shortly thereafter all university travel abroad was suspended. Classes stopped as planned for Spring Break March 16, and in response to the March 15, 2020 declaration of a state of emergency for Oklahoma as well as the city of Stillwater, OSU began limiting access to high-traffic areas such as the University Recreation Center, the OSU Museum of Art, and Student Union dining services.

As students, faculty, and instructors transitioned to Spring Break the week of March 16, 2020, the OSU plan for continuation of the Spring 2020 semester in light of the COVID-19 pandemic included two weeks of online instruction beginning March 23, 2020. Faculty and staff were encouraged to socially distance when on campus, and face-to-face meetings were discouraged. University activities were cancelled until April 5, but the anticipation was that instruction and activities would resume as usual before the end of the Spring 2020 semester. On March 18, 2020, however, OSU announced that classes would be delivered online for the remainder of the Spring 2020 semester.

On March 25, 2020, the University announced closure of all campus buildings, including the Library, as of 6:00pm that evening. The Library continued to provide remote support and access to digital resources for the OSU community, but circulation of physical books and face-to-face interaction was discontinued. Before the Spring 2020 semester ended, it was announced that these precautions would continue throughout the summer, and that the earliest the physical Library building would re-open would be July 7, 2020. Library faculty were permitted to work from home using Library-issued internet connected devices beginning March 13, 2020, and were strongly encouraged to work from home once the building closed March 25, 2020, with building access available to Library faculty only by special request. 


\section{Designing Library OER Interventions}

Rogers (2003) defines interpersonal channels as involving a "face-to-face exchange between two or more individuals" (p. 18). Prior to the abrupt closing of the OSU campus in response to the COVID-19 pandemic, the Library facilitated communication interventions via interpersonal channels by providing workshops, holding individual consultations, assisting with the formation of an OER working group, and through the OER Librarian's participation in meetings and events held on campus. These pre-COVID-19 interventions provided opportunity for communication through both formal and informal interpersonal channels, as many discussions and questions extended beyond the planned workshops, consultations, and meetings into face-to-face conversations that took place in hallways or on sidewalks as individuals transitioned to and from activities (Rogers, 2003). For instance, one major OER project the Library had underway prior to COVID-19 grew out of an informal conversation between the OER Librarian and a department head following an OER working group meeting. Another pre-COVID-19 project had roots in an informal conversation between the OER Librarian and a faculty member when they encountered each other on a campus sidewalk a few weeks after the faculty member had attended a Library led OER workshop. As the Library transitioned to remote services in response to the COVID-19 pandemic, the Library was challenged by the need to remotely facilitate interpersonal communication channels defined by Rogers (2003) as necessarily taking place face-to-face.

\section{Impact on Projects Underway}

Since all University interactions were taking place remotely in response to the COVID-19 pandemic, provision of formal interpersonal communications through interventions such as online OER workshops and OER working group meetings fit in with broadly adopted communication practices. This suggested that existing, pre-COVID-19 interventions could be effectively transitioned online with little modification to design. It quickly became evident, however, that the loss of informal interpersonal communication channels was affecting projects already underway.

\section{Introduction to Social Media}

One of the projects in which this impact was evident was the creation of an open teaching and learning resource for an Introduction to Social Media course, a project in which the Library was working in partnership with the head of the department offering the course. The department head was a member of the OER working group, an intervention designed and implemented following the OER Librarian's human performance technology analysis (Essmiller et al., 2020). Each semester, this department head taught a course with 400 students in one section. He regularly heard stories from his students regarding their perception of and experience with commercial textbooks, and was a strong supporter of the creation and use of OER. He attended a Library session about OER in spring 2018, reviewed a book associated with his content area, and chose to adopt the OER rather than continue using a commercial textbook for the course.

The department head's early adoption of OER qualified him as an innovator (Rogers, 2003), and he actively exercised interpersonal channels to communicate with others regarding OER. Prior to Spring 2020, several courses in his department were shifting from commercial textbooks to OER, and he had initiated partnership with the Library to create OER for the Introduction to Social Media course. The 
resources were to be created by a faculty member in his department, and the department head was providing a point of communication between the creator and the Library. Before the spring 2020 shift to emergency remote teaching, the project was proceeding through the workflow as expected; following the shift, however, progress stalled. Emails were unanswered and it was uncertain phone calls and messages were being forwarded to off campus phones. This silence from a reliable OER partner led the OER Librarian to consider the possibility that interpersonal channels had not shifted online as effectively as hoped, and to consider and anticipate where else these challenges might become apparent.

\section{Nutrition Across the Lifespan}

Another project underway was the creation of teaching and learning resources for a course taught each semester titled "Nutrition Across the Lifespan." The faculty member creating the teaching and learning resource was also the instructor for the course, which had over 100 students in several sections on two campuses. Many of the students were adult students balancing school, work, and family obligations. The faculty member was concerned about the financial impact her use of a commercial textbook was having on her students. She had also become frustrated with what she considered the commercial textbook publisher's violation of her academic freedom, as the publisher attempted to dictate what she included in her syllabus and appeared to require she include course assignments on the publisher's learning platform. She heard about OER via publicity associated with one of the Library's OER creation initiatives implemented in response to the OER Librarian's human performance technology analysis, and after a face-to-face consult with the OER Librarian in Spring 2019 decided to shift from the commercial textbook to OER.

After reviewing resources suggested by the OER Librarian, the faculty member decided to modify an existing OER, customizing it to include information of particular relevance to the local community. The OER Librarian met frequently for face-to-face consultations with the faculty member regarding instructional design and digital technology. These consults were initiated with some regularity by the faculty member, who would email the OER Librarian with general questions, which were then addressed in the face-to-face conversation. As the OER Librarian reviewed projects underway to determine changes in progress similar to what was noticed with the Introduction to Social Media, she realized the nutrition faculty member had not initiated contact since shortly before the COVID-19 pandemic necessitated campus closures. The project was scheduled for completion and implementation Fall 2020, but as the fall semester began the OER Librarian was uncertain of its status.

\section{Dinosaurs}

A third project was accelerated after the switch to emergency remote teaching. The course at the center of this project was an entry-level science course taught through the College of Arts and Sciences. The course was designed to help non-science majors become familiar with the scientific method and develop skills necessary for research and inquiry. Prior to the COVID-19 pandemic, one face-to-face undergraduate section of the course was offered each semester on the main campus.

The faculty member teaching the course attended a face-to-face presentation in which the OER Librarian guided faculty members through an exploration of the characteristics of OER, Creative Commons licenses, where to find OER, and how to create OER. The presentation had been designed and implemented in response to the OER Librarian's human performance technology analysis as an intervention intended to help provide faculty information about OER, discover OER, and clarify faculty understanding 
of OER and digital resources. Faculty and graduate students attending the session were seated together at tables, an arrangement intentionally set to facilitate group engagement with session activities and encourage inter-personal communication.

The faculty member was intrigued by the potential for customization of course material afforded by OER. As she and other faculty attending the face-to-face session worked through the guided exploration of OER and Creative Commons licenses, she mentioned her course and the possibility of using dinosaurs as a 'subject' for the course, with student development of inquiry and research skills being developed as students investigated the history of dinosaurs. Session attendees at her table reacted enthusiastically to the idea, and the faculty member stayed after the session to discuss the potential project with the OER Librarian. The proposal seemed a good fit for the Library's OER initiative, and the Librarian entered the project into the Library's OER development and publication workflow. The faculty member planned to redesign and implement her course in Spring 2020.

As COVID-19 related concerns led to abrupt, mandated campus closures, the faculty member moved her course materials and interactions from face-to-face to fully online. Concerned about whether or not her students had reliable off-campus internet connectivity, she structured class activities to facilitate asynchronous engagement. Rather than requiring students to join online for lengthy synchronous lectures at prescribed times, the faculty member created and recorded a number of shorter videos covering portions of the material which were interspersed with frequent, low-stakes activities providing opportunity to engage with content presented in each video. The activities made use of existing digital technology and were submitted through the campus learning management system. Her students remained engaged throughout the semester and spoke highly of the teaching and learning resources in end of semester course surveys. When the College of Arts and Sciences identified a need for more online courses as COVID-19 related campus closures continued into the summer, they invited the faculty member to present her formerly Fall/Spring face-to-face course as a fully online summer session course. To meet that need, she designed videos and activities for the initial content to complement the resources she had designed for the second half of the Spring 2020 semester. The course was then made available fall, spring, and summer as a fully online course using custom developed OER.

\section{Identification of Performance Gaps}

The impact on projects as described above surfaced challenges introduced to the OSU Library OER initiative as a result of the COVID-19 Pandemic. Interventions had been designed and implemented to support the diffusion of OER by facilitating formal and informal inter-personal communication. A review of overall OER project status suggested that the interventions functioned differently in online spaces. Online OER workshops continued to be offered, the OER working group shifted monthly meetings online, and individual consultations continued to take place online, but stalled progress evident in projects underway indicated the interventions were not affording the same inter-personal communication benefits as the interventions had when implemented in a face-to-face environment. Additionally, once campus closed and interaction moved online, the OER Librarian was called upon for instructional design support and had attended fewer campus meetings and events. Not only had progress stalled on projects underway, but no new projects had begun since COVID-19 related campus closures. The OER Librarian reviewed notes in the OER project workflow through the lens of Diffusion of Innovations Theory to identify points at which the interventions might have failed to effectively transition, attentive 
in particular to how and in what ways informal inter-personal communication, defined by Rogers (2003) as face-to-face conversation, had played a role in furthering the diffusion of OER at OSU.

\section{Before and After Meetings}

Most of the conversations regarding creation of the Introduction to Social Media resources had previously taken place before and after the face-to-face OER working group meetings. The shift to online OER working group meetings had changed the nature of the informal interactions, as they began with attendees joining the online meeting at a precise time and ended with the host clicking a button when the meeting agenda was complete. The presence of a chat function in the online space presented some opportunity for informal inter-personal communication. Meeting attendees could use the chat function to send comments to the entire group or privately to individuals; however, face-to-face meeting etiquette in which visible attentiveness to the speaker communicated respect and credibility inhibited informal communication using the chat function. Remaining online together after the meeting necessitated either permission from or the presence of the host, requiring those who wanted to continue to interact after the meeting to formalize and articulate the request either privately in the chat or publicly in the presence of the entire group.

Online OER workshops began and ended similarly, with the session beginning at a precise time and ending when the presenter or host closed the online space. As with the OER working group meetings, remaining online together after the session itself required submission of a somewhat formal request to the host. While online one-on-one consultations were more flexible, the time together still ended with the click of a mouse and opportunities for informal follow-up were limited.

\section{OER Information Sessions}

The beginning of the project redesign in which the faculty member modified her course to use dinosaurs as the vehicle for development of students' research and inquiry skills could be traced to informal interpersonal communication which took place during a face-to-face OER workshop. The faculty member was able to informally float her idea to the colleagues at her table and gain crucial initial feedback. The informal inter-personal communication with colleagues was interactive, low-stakes, immediate, and motivated her to remain after the session for an informal conversation with the OER Librarian. The faculty member and OER Librarian were able to informally discuss the project and determine whether and how to move forward with formal communications regarding the project.

The born-digital nature of OER meant that the content of OER information sessions could effectively be presented in online spaces. In some cases, the online environment optimized the presentations, as the presenter could share the screen and participants could collaborate in real-time searches for OER materials or experiment with emerging digital resources. As with the OER working group, however, little informal communication took place during the information sessions themselves.

The intentionally interactive nature of the OER workshops invited activity in the chat, but informal chat conversations between or among attendees rarely took place. The nature of the online meeting room meant that attendees were presented somewhat hierarchically, with the presenter as the focus of the session. This was a departure from the atmosphere of the face-to-face OER sessions, where attendees and the presenter sat together at tables and collaborated to explore the content. Minor challenges with technical issues such as whether microphones were muted, background interruptions imposing on the meeting 
presented, and fatigue from inhabiting the online environment on a daily basis may have increased the stakes associated with initiating or responding to interactions. The factors were incremental, but they combined to inhibit informal inter-personal communications during OER sessions.

\section{Sidewalk Conversations}

A review of notes associated with OER projects at various places in the Library OER workflow highlighted the importance of informal inter-personal communications that took place serendipitously as colleagues encountered each other moving across campus. For instance, the OER Librarian parked in the same faculty parking lot as the university provost; chance interactions between the two of them at the end of the day helped sustain progress on a crucial OER publicity campaign. The library could be easily seen from the building housing the office of the faculty member creating resources for the Nutrition Across the Lifespan, serving as a visual reminder of the collaboration. The department head leading the creation of materials for Introduction to Social Media could easily be found in the Union courtyard after teaching a mid-morning course in the Student Union Theatre. Additionally, the fountain and plaza in front of the main campus library served as a focal point and gathering space for formal and informal community activities. These activities provided opportunity for inter-personal communication between and among students and faculty.

The OER Librarian noted that her reduced attendance at campus meetings and events held online as COVID-19 campus closures continued into Fall 2020 had served to limit her interaction with those outside her immediate circle. The librarian was in consistent communication with other librarians in the department and was increasingly connected with faculty seeking assistance with instructional design. She was not, however, connecting with administrators, campus leadership, or faculty and instructors not actively seeking library assistance with emergency remote teaching. This lack of connection with those outside her immediate circle meant that it was possible the only communication administrators and campus leaders were receiving regarding the Library's OER initiative was coming through mass media and formal communication channels rather than the informal inter-personal communication channels previous interventions had targeted. Given the importance of these informal interpersonal communication channels to the Library's effective support of OER, it became apparent that previously designed interventions needed to be modified to align with the needs and affordances of remote interaction.

\section{SOLUTIONS AND RECOMMENDATIONS}

As stated earlier, Diffusion of Innovations Theory examines how innovations are developed, evaluated, adopted, and diffused through a system or organization (Rogers, 2003). Diffusion of Innovations Theory provided a lens through which meaning could be made of COVID-19 related challenges to the Sibrary's OER initiative. The findings of the human performance technology analysis (Essmiller et al., 2020) indicated that inter-personal communications would be most effective in sustaining the diffusion of OER throughout campus. Interventions designed to facilitate inter-personal communication in the face-to-face environment had been implemented and were proving effective. With the abrupt transition to emergency remote teaching during the spring 2020 COVID-19 Pandemic, it became evident that interventions previously designed required modification to effectively facilitate inter-personal communication in online environments. The redesigns included a summer book study, adjustments to processes 
related to the beginning and ending of meetings, increased library presence in OER workshops, and OER presentation opportunities for faculty and staff,.

\section{Summer Book Study}

In order to provide a common space for informal interactions, the Library hosted a summer book study exploring a book describing faculty experiences with OER. The book itself was freely available online, and the study was designed to take place asynchronously with optional opportunities for synchronous conversation in an online video conferencing platform once a week. The online book was linked to an annotation platform, and the thought was that faculty would read the book and engage in conversation using the annotation tools during the week, with synchronous discussion time used to further amplify thoughts and questions which had arisen in the annotations. The book study was publicized at the beginning of the summer to campus stakeholders as part of several library initiatives over the summer. It was hoped that the book study would bring faculty into informal conversations about OER with each other and the Library.

Over ten people registered for the summer book study, and most of them attended the first synchronous session. Participants were given a quick tour of the book and tutorial about how to use the annotation software. Rather than outside imposition of a structured reading schedule, faculty were invited to read and engage with whichever chapters they found most interesting. Although the idea of the study was met with enthusiasm, technical issues with the annotation software hindered its use. Subsequent synchronous sessions were sparsely attended, and the intended goal of increased inter-personal communication did not appear to have been met. A future iteration of this activity will be attempted using a structured reading schedule. It's possible that, rather than providing choice, the open structure added a level of uncertainty which prevented participants from engaging.

\section{Adjustments to Meetings}

In an attempt to replicate the space before and after face-to-face OER working group meetings during which many informal inter-personal communications had taken place, the virtual meeting room began opening ten minutes before the meeting and staying open for a time after the meeting. Meetings were scheduled at specific times, but it was made clear that the room would be open both before and after the meeting. A similar practice was employed for online OER instruction sessions. The OER Librarian was surprised to discover that many attendees did, in fact, join the meeting at the time the room was advertised to be open. During the time before the meeting some would leave both camera and microphone muted, but might join in conversations in the chat window. Others left the camera muted, but the microphone on, and were willing to engage in casual conversations about community issues, pop culture, and even ask about other attendees' pets and children. As participants became aware the room would stay open for a time after the meeting, more began remaining after the agenda was complete to ask follow-up questions or initiate other informal conversations with the presenter, host, or other participants. This adjustment to process did not completely replicate the informal conversations which had taken place before and after face-to-face meetings, but it did provide space which was lacking when the meeting room was only open for the scheduled meeting time itself. 


\section{OER Workshops}

As of this writing, the challenges of creating a collegial, round-table type experience in the video conferencing platform are still in the design process. Break-out rooms do have the effect of creating small groups, but attendees have expressed a sense of isolation as the breakout rooms are no longer seen in the context of the larger group. Other digital technology resources are being explored. OER Workshop attendees had been fairly active in the chat in sessions held online, but it was difficult for the presenter to monitor and engage with the chat while still staying on task with the presentation. In order to increase resources such that the presenter could both engage issues rising in chat and direct the session, the OER Librarian began incorporating student library ambassadors into the OER sessions. The library ambassadors were equipped with a list of tasks to do during the session, such as monitor the waiting room, remind the presenter to record the session, and drop relevant links into the chat as directed. During the session itself, the ambassador monitored the chat, and alerted the presenter to questions or conversations pertinent to the group as a whole. This strategy proved effective. Chat activity increased, and the presenter was able to both attend to session content and engage with attendees. Plans are underway, as well, to incorporate faculty presenters in future OER workshops. It is hoped that this modification will facilitate informal inter-personal communication between faculty and their peers in their departments, furthering the diffusion of OER throughout campus.

\section{Other Meetings and Activities}

Having been reminded of the importance of attendance at campus meetings and events in forming a bridge for inter-personal communication with administration, faculty, and students outside the library, the OER Librarian began consciously following the campus-wide event calendar. When possible, she attended events sponsored by the Institute of Teaching and Learning Excellence, Faculty Council meetings, social events sponsored by the Department of Wellness, and other opportunities as they presented themselves. Inter-personal communication with people outside the library immediately resumed, and the librarian was able to move forward from those points of communication to continue building opportunities for the diffusion of OER. Further evidence of the effectiveness of this modification came in the form of an email contact from someone the librarian had not seen in meetings. This contact had been prompted by a faculty member the librarian had interacted with in an online activity sponsored by the Theatre Department to contact the librarian about OER. This contact indicated that inter-personal communication does in fact play the role suggested by Diffusion of Innovations Theory in the diffusion of OER (Rogers, 2003).

\section{FUTURE RESEARCH DIRECTIONS}

Effective interpersonal communication using online teaching and learning experiences is the result of intentional design and unique strategies. The Spring 2020 switch to emergency remote teaching and learning happened so quickly the Library was challenged to plan and design appropriately. The rate at which it happened meant that there was limited access to the time, resources, and creative energy necessary to implement the shift in a way that took advantage of the unique affordances of the environment (Hodges et al., 2020). Although in March it was hoped the shift to emergency remote teaching would make way 
for a full return to face to face instruction and Library services in the fall (Hodges et al., 2020), it has become clear that options for flexible environments will need to remain available (Beatty, 2020). When educational institutions reopen for face-to-face classes in the future, several circumstances could require pivots back to emergency remote teaching (Ge and Savenye, 2020) or implementation of hybrid-flexible course design models which support both face-to-face and online interaction (Beatty, 2020). Examples include COVID-19 resurges, forcing closures and sheltering in place; schools implement more digital days to aid in social distancing and reducing risk; or students and/or faculty become ill with COVID-19 and must continue coursework online (Lederman, 2020). Given this understanding, the Library will continue to support diffusion of the modification, creation, and publication of OER through interventions designed to facilitate interpersonal communication across and through a variety of spaces.

\section{CONCLUSION}

This chapter described challenges faced by an academic library supporting OER initiatives during the COVID-19 Pandemic. It has detailed interventions as originally designed to support the diffusion of OER, articulated the gaps identified by the Library as interaction moved online, and described the interventions as redesigned and implemented. Redesigns included processes such as the OER Librarian logging on early to meetings in order to make space for pre- meeting conversations, waiting to end meetings to make space for post meeting conversations, and the use of Library ambassadors to help with online workshops so that the OER Librarian had more flexibility for inter-personal communication and followup. Redesigns also included products such as partnerships to create a state wide informal interpersonal communication channel, OER teaching and learning opportunities intentionally including faculty as presenters which have the side benefit of facilitating informal conversations between the Library and faculty, and a summer book study bringing faculty into informal conversation with each other and the Library. Future interventions will include options for inter-personal communication, which are remote but not online, and opportunities for campus faculty to more fully engage with statewide OER activities.

\section{REFERENCES}

Bali, M., Cronin, C., \& Jhangiani, R. S. (2020). Framing Open Educational Practices from a Social Justice Perspective. Journal of Interactive Media in Education, 2020(1), 10. doi:10.5334/jime.565

Beatty, B. (2020, May 26). Can HyFlex options support students in the midst of uncertainty? Transforming Higher Ed. https://er.educause.edu/blogs/2020/5/can-hyflex-options-support-students-in-the-midstof-uncertainty

Belikov, O., \& Bodily, R. (2016). Incentives and barriers to OER adoption: A qualitative analysis of faculty perceptions. Open Praxis, 8(3), 235-246. doi:10.5944/openpraxis.8.3.308

Cuillier, C. (2018). Overcoming objections to OER from faculty and administrators. Digital Initiatives Symposium, 27. Retrieved from https://digital.sandiego.edu/symposium/2018/2018/27 
DiSanto, J., Cummings-Clay, D., Mitchell, S., \& Ford, M. (2020). Beyond saving money: Engaging multiple stakeholders is a key to OER success. The International Journal of Open Educational Resources, 2(1). Advance online publication. doi:10.18278/ijoer.2.1.14

Essmiller, K., Thompson, P., \& Alvarado-Albertorio, F. (2020, March). Performance improvement technology for building a sustainable OER initiative in an academic library. TechTrends, 64(2), 265-274. doi:10.100711528-019-00467-2

Hess, J., Nann, A. J., \& Riddle, K. E. (2016). Navigating OER: The library's role in bringing Oer to campus. The Serials Librarian, 70(1-4), 128-134. doi:10.1080/0361526X.2016.1153326

Huang, R., Liu, D., Tlili, A., Knyazeva, S., Chang, T. W., Zhang, X., Burgos, D., Jemni, M., Zhang, M., Zhuang, R., \& Holotescu, C. (2020). Guidance on Open Educational Practices during School Closures: Utilizing OER under COVID-19 Pandemic in line with UNESCO OER Recommendation. Smart Learning Institute of Beijing Normal University.

Jenkins, J. J., Sanchez, L. A., Schraedley, M. A. K., Hannans, J., Navick, N., \& Young, J. (2020). Textbook broke: Textbook affordability as a social justice issue. Journal of Interactive Media in Education, 2020(1), 3. doi:10.5334/jime.549

Larson, A. (2020). Open education librarianship: A Position Description Analysis of the Newly Emerging Role in Academic Libraries. International Journal of Open Educational Resources. https://www. ijoer.org/open-education-librarianship-a-position-description-analysis-of-the-newly-emerging-role-inacademic-libraries/

Lashley, J., Cummings-Sauls, R., Bennett, A. B., \& Lindshield, B. L. (2017). Cultivating textbook alternatives from the ground up: One public university's sustainable model for open and alternative educational resource proliferation. The International Review of Research in Open and Distributed Learning, 18(4). Advance online publication. doi:10.19173/irrodl.v18i4.3010

Lederman, D. (2020). The shift to remote and what's ahead for fall: Your turn. Inside Higher Ed. https:// www.insidehighered.com/digital-learning/article/2020/05/06/instructors-describe-impact-shift-remotecolleges-quarter-system

Miao, F., Mishra, S., Orr, D., \& Janssen, B. (2019). Guidelines on the development of open educational resources policies. UNESCO Publishing.

Nusbaum, A. (2020). Who gets to wield academic Mjolnir? On worthiness, knowledge curation, and using the power of the people to diversify OER. Journal of Interactive Media in Education, 1(4), 1-9. doi:10.5334/jime.559

Oklahoma State University. (2020). Coronavirus monitoring: TravelRestrictions Update. https://go.okstate. edu/coronavirus/latest-announcements/coronavirus-monitoring-travel-restrictions-update.html

OkState Library. (2019, September 3). Join the \#openokstate movement [Video]. YouTube. https://www. youtube.com/watch? $\mathrm{v}=$ lyiAl $1 \mathrm{Vc} 2 \mathrm{Bc}$

Reed, J. B., \& Jahre, B. (2019). Reviewing the current state of library support for Open Educational Resources. Collection Management, 44(2-4), 232-243. doi:10.1080/01462679.2019.1588181 
Rogers. (2003). Diffusion of Innovations (5th ed.). New York: Free Press.

Sandy, H. M., \& Mattern, J. B. (2018). Academic library-based publishing: A state of the evolving art. Library Trends, 67(2), 337-357. doi:10.1353/lib.2018.0040

Santiago, A., \& Ray, L. (2020). Navigating support models for OER publishing: Case studies from the University of Houston and the University of Washington. Reference Services Review. ahead-of-print. doi:10.1108/RSR-03-2020-0019

Seaman, J. E., \& Seaman, J. (2018). Freeing the Textbook: Educational Resources in U.S. Higher Education, 2018. https://www.onlinelearningsurvey.com/reports/freeingthetextbook2018.pd

Soper, D., Wharton, L., \& Phillips, J. (2018). Expediting OER on campus: A multifaceted approach. In K. Jensen \& S. Nackerud (Eds.), The evolution of affordable content efforts in higher education: Programs, case studies and examples. University of Minnesota Libraries.

Van Tiem, D., Moseley, J. L., \& Dessinger, J. C. (2012). Fundamentals of performance improvement: Optimizing results through people, process, and organizations. John Wiley \& Son.

Walsh, A. J. (2020). Removing barriers: textbook affordability and OER at Sinclair community college. Academic Press.

World Health Organization. (2020). Naming the coronavirus disease (COVID-19) and the virus that causes it. Retrieved October 8, 2020, from https://www.who.int/emergencies/diseases/novel-coronavirus-2019/ technical-guidance/naming-the-coronavirus-disease-(covid-2019)-and-the-virus-that-causes-it

\section{ADDITIONAL READING}

Almeida, N. (2017). Open educational resources and rhetorical paradox in the neoliberal univers(ity). Journal of Critical Library and Information Studies, 1(1). Advance online publication. doi:10.24242/ jclis.v1i1.16

Anderson, T., Doney, J., Hendrix, B., Martinez, J., Stoddart, R., \& Wright, M. (2019). The five laws of OER: Observations from Ranganathan. Journal of Librarianship and Scholarly Communication, 7(1). Advance online publication. doi:10.7710/2162-3309.2299

Chetna, N. (2019). The social construction of openness: Open textbooks and their interpretations. International Journal of Technology, Knowledge and Society, 15(3), 21-41.

Clinton, V., \& Khan, S. (2019). Efficacy of open textbook adoption on learning performance and course withdrawal rates: A meta- analysis. AERA Open, 5(3), 21-41. doi:10.1177/2332858419872212

Cronin, C. (2017). Openness and praxis: Exploring the use of open educational practices in higher education. International Review of Research in Open and Distributed Learning: IRRODL, 18(5), 15-34. doi:10.19173/irrodl.v18i5.3096 
Hilton, J. (2019). Open educational resources, student efficacy, and user perceptions: A synthesis of research published between 2015 and 2018. Educational Technology Research and Development, 1-24. doi:10.100711423-019-09700-4

Nusbaum, A. T. (2020). Who Gets to Wield Academic Mjolnir?: On Worthiness, Knowledge Curation, and Using the Power of the People to Diversify OER. Journal of Interactive Media in Education, 2020(1), 4. doi:10.5334/jime.559

Wiley, D., Bliss, T. J., \& McEwen, M. (2014). Open educational resources: A review of the literature. In Handbook of research on educational communications and technology (pp. 781-789). Springer. doi:10.1007/978-1-4614-3185-5_63

\section{KEY TERMS AND DEFINITIONS}

Academic Library: A library intentionally aligned with a specific institution of higher education.

Diffusion: The "social change" (Rogers, 2003, p. 6) which takes place as members of a social system share information regarding an innovation.

Diffusion of Innovations Theory: A communications theory useful for understanding the diffusion of new ideas or practices among individuals or organizations.

Human Performance Technology: A process bridging the gap between existing conditions and desired conditions in complex organizations.

Innovation: An idea or practice perceived as new to an individual or organization.

Interpersonal Communication: Communication exchange between two or more people.

Intervention: In human performance technology, a results-oriented and comprehensive strategy designed to achieve desired performance in a system.

Open Educational Practices: Teaching and learning strategies which de-center the instructor and actively involve students in knowledge construction through engagement with content to create experiences and artifacts of benefit to the community beyond the classroom.

Open Educational Resources: Teaching, learning, and research materials intentionally created to be free for the end user to retain, distribute, and in most cases, modify.

Technology: A process through which problems are identified and solved. 